\title{
A systematic review of depression and anxiety in medical students in China
}

\author{
Ying Mao ${ }^{1 *}$, Ning Zhang ${ }^{1}$, Jinlin Liu', Bin Zhu ${ }^{1,2}$, Rongxin $\mathrm{He}^{1}$ and Xue Wang ${ }^{1}$
}

\begin{abstract}
Background: Medical students in China face severe depression and anxiety because of their difficult circumstances, such as the long length of schooling, academic pressure, and the stress of clinical practice. Although there have been many empirical studies about depression or anxiety in medical students in China, no previous studies have conducted a related systematic review about this topic in English. This analysis can convey the general findings from China to other areas of the world.

Methods: A systematic review and meta-analysis of depression or anxiety in medical students and related determinants were conducted. Three Chinese and three English databases were searched for the review, with no restrictions on language. Articles published between January 1, 2000 and April 1, 2018 were included.

Results: Twenty-one articles investigating a total of 35,160 individual Chinese medical students were included in this review. The prevalence of depression ranged from 13.10 to $76.21 \%$ with a mean of $32.74 \%$, and the prevalence of anxiety ranged from 8.54 to $88.30 \%$ with a mean of $27.22 \%$. Based on the meta-analysis, gender, grade level, residence, satisfaction with current major and monthly household income per capita were significantly associated with depression. Grade level and satisfaction with current major were significantly associated with anxiety. Other risk factors were identified and described using a narrative approach.
\end{abstract}

Conclusion: The mean prevalence of depression was $32.74 \%$ amongst medical students in China, whereas the mean prevalence of anxiety was $27.22 \%$. The determinants of depression and anxiety included individual factors, social and economic factors, and environmental factors. More measures should be taken towards at-risk medical students based on the identified risk factors.

Keywords: Depression, Anxiety, Medical students, Systematic review, Meta-analysis

\section{Background}

Depression and anxiety are amongst the most frequent mental disorders. Mental disorders have received increasing global attention because of their negative effects on working ability and the performance of people. As the core of the health system in all countries [1], medical workers are suffering from depression or anxiety resulting from their deteriorative treatment environment (i.e., workplace violence) [2], overwork [3], burnout [4], huge academic pressure [5], declining job satisfaction [6], etc.

Similarly, as the successors of medical workers, medical students have reported experiencing a higher level of depression or anxiety compared to their peers [7].

\footnotetext{
* Correspondence: mao_ying@mail.xjtu.edu.cn

${ }^{1}$ School of Public Policy and Administration, Xi'an Jiaotong University, Xi'an

710049, China

Full list of author information is available at the end of the article
}

Medical students should be fully aware of the difficulties before entering into the job market. During the study portion of medical school, which is seemingly relaxed and enjoyable, medical students still experience huge pressure, such as the stress of the long length of schooling, academic pressure, the stress of clinical practice, etc. [8]. $27.2 \%$ of medical students, as reported by Rotenstein et al., were subjected to depression or depressive symptoms in 47 countries. [9]. Different prevalence results have been found in many other countries and regions [10-12]. However, the determinants of depression and anxiety are similar, according to previous studies $[13,14]$.

Several studies have explored the effects of various risk factors of depression and anxiety in medical students, such as age [9-11], gender $[5,15]$, grade [4], ethnicity $[14,16]$, residence $[17,18]$, current major $[19,20]$, school

(c) The Author(s). 2019 Open Access This article is distributed under the terms of the Creative Commons Attribution 4.0 International License (http://creativecommons.org/licenses/by/4.0/), which permits unrestricted use, distribution, and reproduction in any medium, provided you give appropriate credit to the original author(s) and the source, provide a link to the Creative Commons license, and indicate if changes were made. The Creative Commons Public Domain Dedication waiver (http://creativecommons.org/publicdomain/zero/1.0/) applies to the data made available in this article, unless otherwise stated. 
[21], learning stage [22, 23], length of schooling [24], being an only child [18-21], rating of school [22, 23, 25], satisfaction with current major [26], attitude towards future career [27, 28], academic pressure [29], smoking addiction [26], alcoholism [26], school loans [21, 25], clinical internship [30], the ability to deal with interpersonal relationships [19, 22], parents' education [24], parental occupational status [31, 32], family financial status [27-29], social support factors and other factors [33].

In the Chinese context, medical students also suffer from severe mental diseases, particularly depression and anxiety, which mainly caused by the huge pressure during school [34-36], the extremely long length of schooling [7], and worries about horrible working conditions, such as the stressful relationship between patients and doctors [37]. Many empirical studies have been conducted in China; however, most of them were published in Chinese journals, and no related systematic reviews have been found.

Based on the above findings, this study aimed to examine the prevalence of depression or anxiety amongst medical students in China by conducting a systematic review and a systematic research study about their determinants.

\section{Methods}

A systematic review was conducted based on studies published in English and Chinese databases from January 1, 2000 to April 1, 2018, following the Preferred Reporting Items for Systematic Reviews and Meta-Analyses (PRISMA) guidelines [38]. We searched the following English databases: PubMed, EMBASE and Cochrane Library; we also searched the following Chinese databases: China National Knowledge Internet Database (CNKI), Wanfang database, and China Biology Medicine $\operatorname{disc}(\mathrm{CBM})$.

\section{Search strategy and selection criteria}

For the three English databases, i.e., PubMed, EMBASE and Cochrane Library, we used a search strategy based on a combination of the following terms: [(undergraduate medical student) OR (medical student) OR (Trainee doctor) OR (student doctor)] AND [(Depression) OR (Major depressive disorder) OR (Depressive disorder) OR (Anxiety)] AND [(China) OR (Chinese)].

For the three Chinese databases, i.e., China National Knowledge Internet Database (CNKI), Wanfang database, and China Biology Medicine disc (CBM), we used a combination of the following terms: [zhong-guo OR zhong-guo-de] (China/Chinese) AND [yi-xue-sheng OR shi-xi-yi-sheng OR yi-xue-zhuan-ye-xue-sheng] (Medical students/Trainee doctor/undergraduate medical students) AND [yi-yu OR jiao-lv] (Depression/anxiety).

The search strategy is shown in Additional file 1.
The eligibility criteria included the following: (1) Time and location: the systematic review included published articles (without language restrictions) conducted in China between January 1, 2000 and April 1, 2018. (2) Study participants: the study population was comprised of medical students. (3) Studies that measured the degree of depression or anxiety using validated assessment tools. (4) Studies that analysed related determinants of depression or anxiety in medical students. (5) Studies that reported on the pressure of medical students under emergency or special circumstances (earthquakes, severe acute respiratory syndromes, etc.) were excluded. (6) Only cross-sectional studies were included.

\section{Data analysis}

Two independent reviewers participated in the data extraction by screening the acquired studies at the same time, according to the flow diagram (shown in Fig. 1). Disagreements were resolved through discussions between the two reviewers and full group consensus. The basic information extracted from each included study contained the first author, year of publication, locations, participants, mental problem types, sample size, qualified rate, assessment tools, disease incidence cases, incidence rates and the number of references (shown in Table 1).

The quality of evidence was assessed using the Grading of Recommendations: Assessment, Development, and Evaluation (GRADE) approach [61] for observational studies. The quality assessment standard of the studies evaluated the representativeness of the sample, sample size, non-respondents, ascertainment of the exposure, comparability of subjects in different outcome groups, assessment of the outcome, and use of appropriate statistical test (shown in Table 2). The maximum score was 7 , a score of 5-7 indicated good quality, a score of 3-4 indicated medium quality, and a score of 1-2 indicated poor quality. Studies with medium and good quality were included in our analysis.

\section{Synthesis of results}

This study adopted the framework of the social determinants of health (SDH), which were proposed by the 66th World Health Assembly of the World Health Organization (WHO), to synthesize the results [81]. "The SDH are the conditions in which people are born, grow, work, live, and age, and the wider set of forces and systems shaping the conditions of daily life. These forces and systems include economic policies and systems, development agendas, social norms, social policies and political systems" [82]. According to the framework, apart from the direct influencing factors, there are other factors in a social structure such as class, power and wealth. These factors were collectively referred to as environmental characteristics. Mental health is also a part of overall health. Previous scholars have 


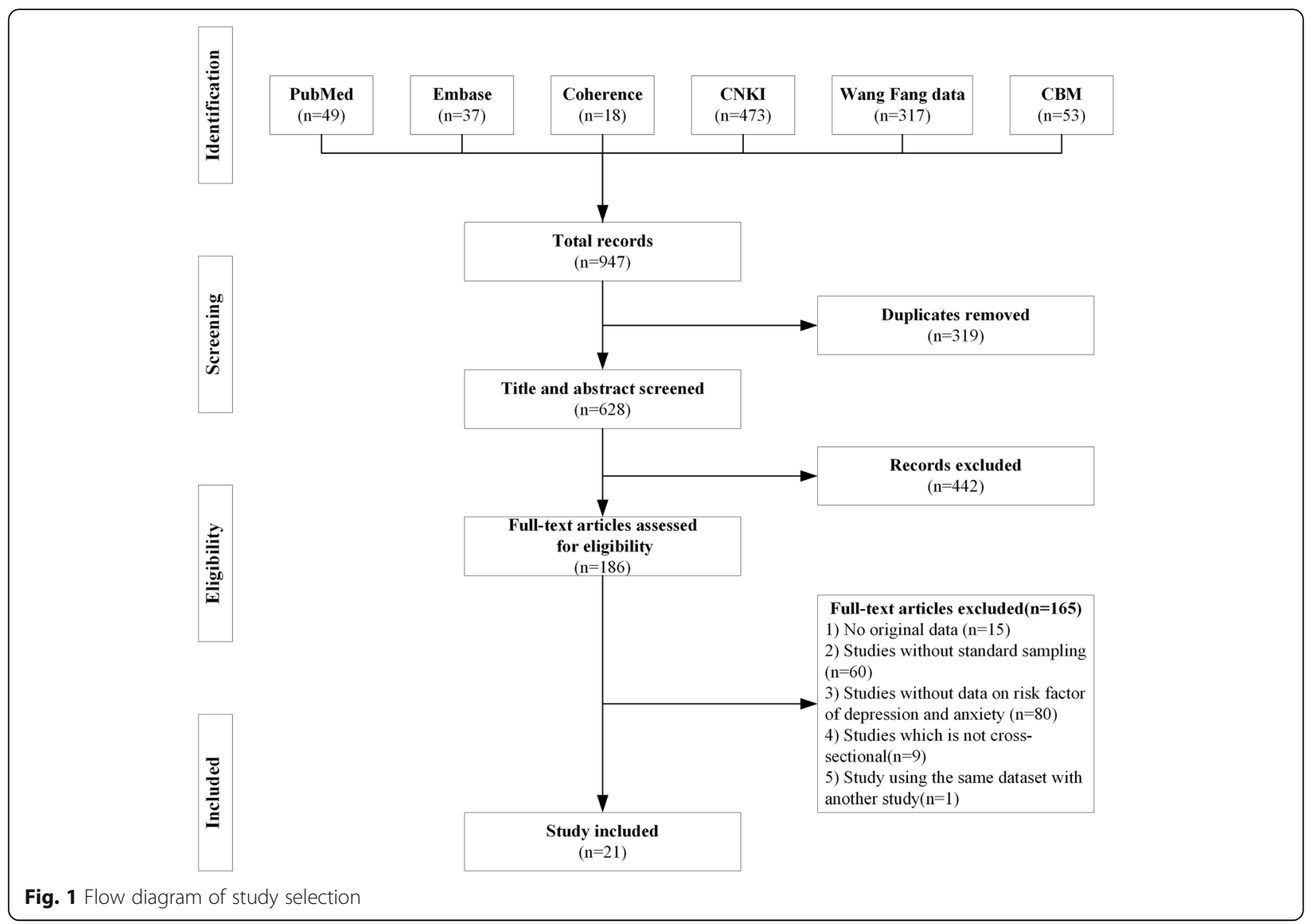

identified an association between mental health and social determinants [83, 84]. Based on the conceptual framework and the WHO guidelines of the determinants of mental health, the determinants of medical students' mental health (depression or anxiety) were categorized into three parts: individual factors (IFs) (including biological factors, psychological factors, and behavioural factors), social and economic factors (SEFs) (including relationship with others and economic status) and environmental risk factors (EFs) (including inequality, racism, discrimination, refugee, war and immigrants).

\section{Statistical analysis}

Two main outcomes were evaluated. The first outcome was the prevalence and determinants of depression analysis, whereas the second outcome assessed the prevalence and determinants of anxiety. Not all the determinants were included in the meta-analysis. It was required that were the same or could be merged into the same category. The variable screening process is shown in Additional file 1. In this study, the different variables were transformed into binary variables; meanwhile, the included determinants were those reported in at least two articles.
The determinants included in the meta-analysis were those reported in at least three articles. In the meta-analysis, the significance of the pooled odds ratio (OR) was determined by the Z-test, with a $P<0.05$ considered statistically significant. The $Q$ statistic was calculated to estimate the heterogeneity, and $P \leq 0.10$ was considered statistically significant [85]. A fixed-effect model was used to compute the summary risk estimate. We assessed the possibility of publication bias for the studies included in the meta-analyses with Egger's linear regression test, which was used to quantitatively evaluate the asymmetry. In this study, all the significance levels were set at $p$-value $<0.05$. The null hypothesis is that there is no difference between variable values. The null hypothesis is rejected when $p<0.05$ and not rejected when $p>0.05$.

Forest maps were created to illustrate the results and significance of the included articles. In the plane Cartesian coordinate system, the forest map uses a vertical equivalent line as the centre and describes the results and confidence intervals of each included study via multiple lines parallel to the horizontal axis. The forest map uses a diamond, which is the black quadrilateral shown in the map, to describe the results and confidence intervals of multiple studies. 
Table 1 Tools used to assess medical students' mental health and determinants

\begin{tabular}{|c|c|c|c|c|}
\hline Assessment tools & $\begin{array}{l}\text { Assessment tool } \\
\text { (abbreviated) }\end{array}$ & Standard & Studies (n) & Ref. No \\
\hline \multicolumn{5}{|l|}{ Depression } \\
\hline Beck Depression Inventory & $\mathrm{BDI}$ & $\begin{array}{l}\text { A score of } \geq 14 \text { out of } 84 \\
\text { indicates depression }\end{array}$ & 3 & [39] \\
\hline Centre for Epidemiologic Studies Depression Scale & CES-D & $\begin{array}{l}\text { A score of } \geq 15 \text { out of } 60 \\
\text { indicates depression }\end{array}$ & 4 & [40] \\
\hline Zung self-rating Depression Scale & SDS & $\begin{array}{l}\text { A score of } \geq 40 \text { out of } 80 \\
\text { indicates depression }\end{array}$ & 8 & [41] \\
\hline \multicolumn{5}{|l|}{ Anxiety } \\
\hline Symptom Checklist 90 & SCL-90 & $\begin{array}{l}\text { A score of } \geq 1.8 \text { out of } 5 \\
\text { indicates anxiety }\end{array}$ & 2 & [42] \\
\hline Beck Anxiety Inventory & BAl & $\begin{array}{l}\text { A score of } \geq 5 \text { out of } 63 \\
\text { indicates anxiety }\end{array}$ & 1 & [43] \\
\hline Zung Self-rating Anxiety Scale & SAS & $\begin{array}{l}\text { A score of } \geq 40 \text { out of } 80 \\
\text { indicates anxiety }\end{array}$ & 6 & [44] \\
\hline Hamilton Anxiety Rating Scale & HAMA & $\begin{array}{l}\text { A score of } \geq 14 \text { out of } 56 \\
\text { indicates anxiety }\end{array}$ & 3 & [45] \\
\hline \multicolumn{5}{|l|}{ Determinants } \\
\hline Perceived Social Support Scale & PSSS & - & 2 & [46] \\
\hline Eysenck Personality Questionnaire & EPQ & - & 2 & [47] \\
\hline Life Events Scale & LES & - & 1 & [48] \\
\hline China College Student Adjustment Scale & CCSAS & - & 1 & [49] \\
\hline Life Orientation Test-Revised & LOT-R & - & 1 & [50] \\
\hline Resilience Scale-14 & RS-14 & - & 1 & [51] \\
\hline Adult Dispositional Hope Scale & $\mathrm{ADHS}$ & - & 1 & [52] \\
\hline Social Support Rating Scale & SSRS & - & 2 & [53] \\
\hline Family APGAR Index & APGAR & - & 1 & [54] \\
\hline Student-life Stress Inventory & SLS & - & 1 & [55] \\
\hline Coping Style Questionnaire & CSQ & - & 1 & [56] \\
\hline $\begin{array}{l}\text { The Medical Outcomes Study 36-Item Short-form } \\
\text { Health Survey }\end{array}$ & SF-36 & - & 1 & [57] \\
\hline Beck Hopeless Scale & $\mathrm{BHS}$ & - & 1 & [58] \\
\hline Adolescent Self-Rating Life Events Check List & ASLEC & - & 1 & [59] \\
\hline The Pittsburgh Sleep Quality Index & PSQI & - & 1 & {$[60]$} \\
\hline
\end{tabular}

Using gender (shown in Fig. 2) as an example, there was no significant difference between males and females, as shown by the horizontal lines crossing the vertical line. When horizontal lines were located to the left of the vertical line, females displayed more depressive symptoms than males. When the horizontal lines were located to the right of the vertical line, the reverse case was true.

If it was impossible to perform a quantitative synthesis and conduct a meta-analysis, we used the narrative approach and descriptive statistics, which reported the same determinants, and compared their associations with depression or anxiety.

All statistical analyses were performed using Stata 13.0 (Stata Corp, College Station, TX, USA) and RevMan 5.3 (The Cochrane Collaboration, Oxford, UK).

\section{Results}

\section{Search results}

The study selection process was shown in Fig. 1. This study was conducted according to the PRISMA flow diagram and included four stages: identification, screening, eligibility and inclusion. The initial database search identified 947 articles; after removing duplicate records, 628 remained. The two reviewers examined the remaining articles by screening the titles and abstracts. In total, 186 articles were included in the full-text review. Amongst these studies, 15 articles were eliminated because they lacked original data, 60 articles were removed because they lacked standard sampling, 80 articles were removed because they did not analyse the determinants of depression or anxiety, nine articles were not cross-sectional, 


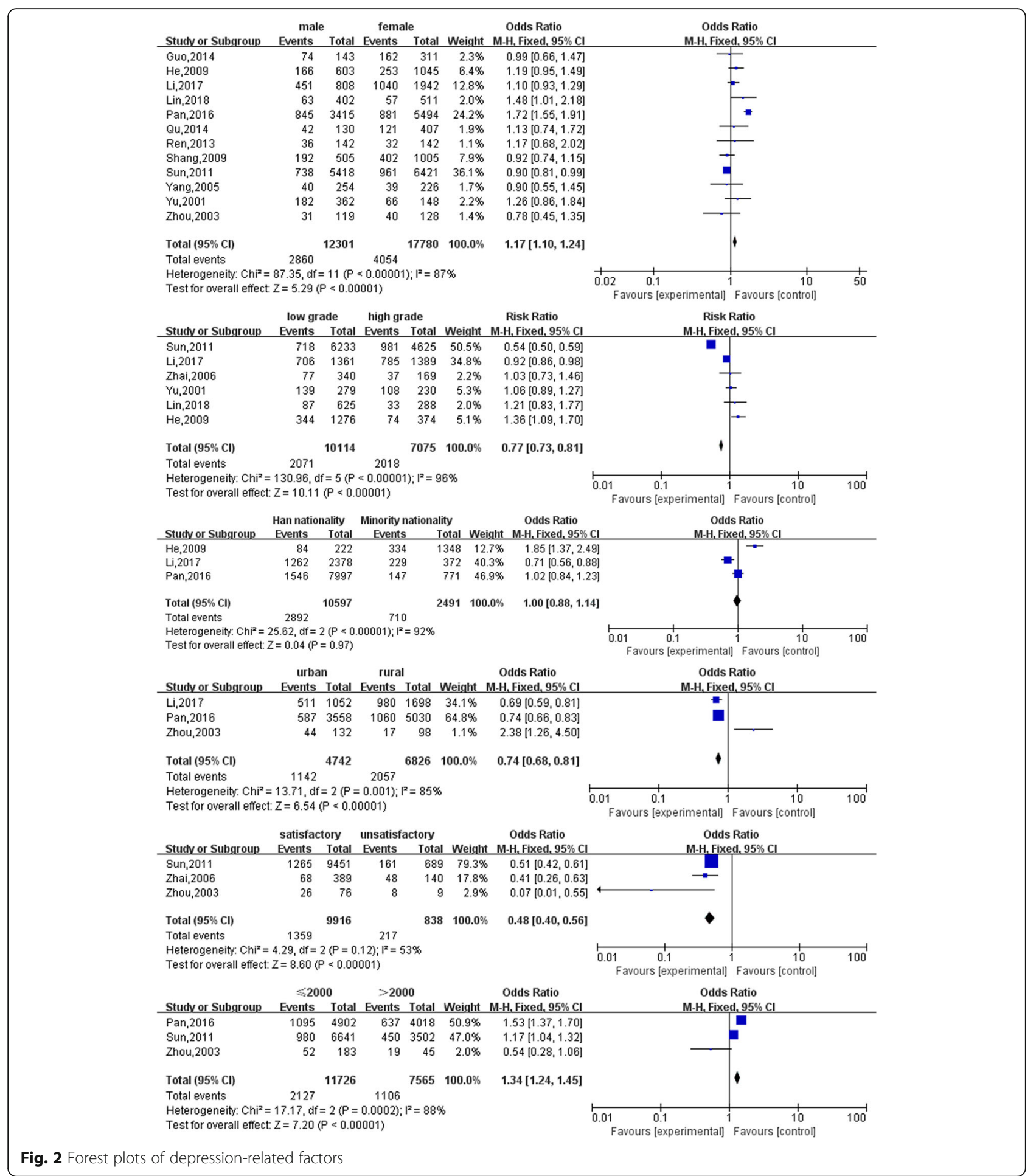

and two articles used the same database. Finally, 21 studies were included in this study.

\section{Analysis of the included articles}

Table 1 presents the full name and abbreviated name of the assessment tools utilized in the 21 articles. The included articles utilized three depression assessment tools, four anxiety assessment tools, and 15 determinants assessment tools. Table 3 presents the basic features of the individual studies. The 21 articles contained 35,160 individual participants distributed in the 23 provinces. Two articles included an analysis of 
Table 2 Quality scores assessing the risk of bias using a modified Newcastle-Ottawa scale

\begin{tabular}{|c|c|c|c|c|c|c|c|c|}
\hline \multicolumn{9}{|c|}{ Study type: Cross-sectional; Score: 1 = achieved, $0=$ not achieved } \\
\hline Authors & $\begin{array}{l}\text { Representativeness } \\
\text { of the sample }\end{array}$ & $\begin{array}{l}\text { Sample } \\
\text { size }\end{array}$ & Non-respondents & $\begin{array}{l}\text { Ascertainment } \\
\text { of the exposure }\end{array}$ & $\begin{array}{l}\text { Comparability of } \\
\text { subjects in different } \\
\text { outcome groups } \\
\text { (control for } \\
\text { confounding) }\end{array}$ & $\begin{array}{l}\text { Assessment of } \\
\text { the outcome }\end{array}$ & $\begin{array}{l}\text { A statistical test } \\
\text { is appropriate }\end{array}$ & $\begin{array}{l}\text { Total } \\
\text { score }\end{array}$ \\
\hline Lin, 2018 [62] & 0 & 1 & 1 & 1 & 1 & 1 & 1 & 6 \\
\hline Li, 2017 [63] & 1 & 1 & 1 & 1 & 1 & 1 & 1 & 7 \\
\hline Pan, 2016 [64] & 1 & 1 & 0 & 1 & 1 & 1 & 1 & 6 \\
\hline Li, 2015 [65] & 0 & 1 & 1 & 1 & 1 & 1 & 1 & 6 \\
\hline Li, 2015 [66] & 1 & 1 & 1 & 1 & 1 & 1 & 1 & 7 \\
\hline Zhai, 2006 [67] & 0 & 1 & 1 & 1 & 1 & 1 & 1 & 6 \\
\hline Guo, 2014 [35] & 0 & 1 & 1 & 1 & 1 & 1 & 1 & 6 \\
\hline Ren, 2013 [68] & 0 & 1 & 1 & 1 & 1 & 1 & 1 & 6 \\
\hline Ruan, 2011 [69] & 0 & 1 & 0 & 1 & 1 & 1 & 1 & 5 \\
\hline Sun, 2011 [70] & 1 & 1 & 1 & 1 & 1 & 1 & 1 & 7 \\
\hline Feng, 2010 [71] & 0 & 1 & 1 & 1 & 1 & 1 & 1 & 6 \\
\hline Shang, 2009 [72] & 1 & 1 & 1 & 1 & 1 & 1 & 1 & 7 \\
\hline Li, 2009 [73] & 0 & 1 & 1 & 1 & 1 & 1 & 1 & 6 \\
\hline He, 2009 [74] & 0 & 1 & 1 & 1 & 1 & 1 & 1 & 6 \\
\hline Liu, 2009 [75] & 0 & 1 & 1 & 1 & 1 & 1 & 1 & 6 \\
\hline Liang, 2007 [76] & 0 & 1 & 1 & 1 & 1 & 1 & 1 & 6 \\
\hline Qu, 2014 [34] & 0 & 1 & 1 & 1 & 1 & 1 & 1 & 6 \\
\hline Yang, 2005 [77] & 0 & 1 & 1 & 1 & 1 & 1 & 1 & 6 \\
\hline Zhou, 2003 [78] & 0 & 1 & 1 & 1 & 1 & 1 & 1 & 6 \\
\hline Yu, 2001 [79] & 0 & 1 & 0 & 1 & 1 & 1 & 1 & 5 \\
\hline Wu, 2000 [80] & 1 & 1 & 1 & 1 & 1 & 1 & 1 & 7 \\
\hline
\end{tabular}

different cities, and the others investigated one individual city.

All 21 articles were conducted in medical colleges or universities (two in medical colleges and 19 in medical universities). One study focused on undergraduate students in a Chinese traditional medical school, one article analysed undergraduate students who were minorities, one article evaluated the mental health of freshmen students, and two articles studied college medical students. The other studies focused on undergraduate medical students in general.

Ten articles analysed the prevalence and determinants of depression [35, 62-64, 72, 73, 78-80], six articles analysed the prevalence and determinants of anxiety $[65,66$, $69,71,75,76]$, and five articles included an analysis of both depression and anxiety [34, 67, 70, 74, 77].

Fifty-seven determinants were extracted, which were determined based on their associations with depression or anxiety in medical students in the 21 included studies (shown in Additional file 1). According to the SDH and WHO guidelines, the determinants of mental health [83] were categorized into three groups: (1) 30 individual factors: gender, grade, age, ethnicity, residence, current major, type of school, school location, learning stage, length of schooling, number of siblings, rating of school, satisfaction with current major, attitude towards future career, academic pressure, clinical internship, retaking college entrance examination as a senior, personal character score, adaptability factor score, interest in current major, satisfaction with school life, satisfaction with accommodations, sleeping conditions, feelings of loneliness, smoking addiction, alcoholism, academic grade, ideation of suicide, exercise, and having a part-time job; (2) 25 social and economic factors: father's education level, mother's education level, father's employment, mother's employment, monthly household income per capita (yuan), single parent, ability to deal with interpersonal relationships, school loans, strained relationship with classmates and friends, strained relationship with teacher, strained relationship with parents, uncomfortable relationship with people of the opposite sex, bad employer, being disappointed in love, being discriminated against, being criticized or misunderstood, having sincere friends, death of relatives, acute and serious illness of relatives, emergency of a family member, lack of psychological 
guidance, family medical history, number of home moves, parental rearing behaviour, and parental attention level; and (3) 2 environmental factors: social support and unsatisfaction with social phenomenon.

\section{Quality of the included articles}

The determinants of depression or anxiety were analysed via a meta-analysis and content analysis. The average score of the included articles was 6.14 out of 7 according to the modified Newcastle-Ottawa scale (shown in Table 2). All studies were of medium and high quality. Fifteen articles did not meet the standard of representativeness of the sample (sample size $\geq 1000$ participants). Three articles did not report the non-respondents or reported a response rate of less than $80 \%$. All articles met the other conditions. The quality assessment for this systematic review is shown in Table 2.

\section{Analysis of depression}

In the 21 identified articles, 15 reported the prevalence of depression. Based on the 15 studies, the prevalence of depression ranged from 13.10 to $76.21 \%$, as shown in Table 3. The mean prevalence of depression was $32.74 \%$. However, different studies used different assessment tools. For example, the Beck Depression Inventory (BDI) defined a score of $>5$ out of 63 to indicate depression. The Centre for Epidemiologic Studies Depression Scale (CES-D) defined a score of $>15$ out of 60 to indicate depression. The Self-rating Depression Scale (SDS) defined a score of $>40$ out of 80 to indicate depression.

Amongst all the determinants evaluated, the depression analysis extracted 31 determinants, including 24 individual factors, six social and economic factors, and one environmental factor.

Six of the individual factor determinants were included in the meta-analyses whereas all the extracted determinants were included in the descriptive analysis. Figure 2 shows the meta-analysis results of the depression-related individual factors. Gender (male vs female, OR: 1.17, 95\% CI: 1.10-1.24), grade level (low grade vs high grade, OR: $0.77,95 \%$ CI: 0.73-0.81, $P<0.001$ ), residence (rural vs urban: OR: $0.74,95 \%$ CI: $0.68-0.81, P<0.001$ ), and satisfaction with current major (satisfied vs unsatisfied: OR: $0.48,95 \%$ CI: $0.40-0.56, P<0.001)$ were significantly associated with depression in medical students. Ethnicity was not significantly associated with depression in medical students. The studies found that male students, higher grade level students, and students who were unsatisfied with their current majors were more depressed than their peers $[62,64,74]$.

Medical students who had an increased odds of having depression were those who had siblings [63, 74] and were from rural areas [63]. Higher depressive symptoms were also reported in medical students with smoking $[64,68]$ and drinking $[64,68]$ habits, poor adaptability [62], sleep deprivation [64, 77], a longer length of schooling [64], and in those who had been hospitalized or received medication for 1 week or more in the last 4 weeks [64], were in a lower academic grade level [72], had a bad self-evaluation of mental health [35, 72], had a higher frequency of participating in association activities [35], had a higher interest [35, 78] and satisfaction [70] with their current major, had a pessimistic anticipation of their future career [35], had greater academic pressure $[35,68,78]$, and experienced the ideation of suicide [72].

When evaluating school aspects, the students in traditional Chinese medical schools or comprehensive schools [64] experienced higher levels of depression symptoms [66]. Regarding current major, pharmacy students [34, 72] and nursing students [34] were more depressed than their peers. Previous studies have not reached the same conclusions regarding the above issues.

One of the social and economic factor determinants was analysed in the meta-analysis whereas all the extracted determinants were included in the descriptive analysis. Figure 2 shows the meta-analysis results of the depression-related social and economic factors. The monthly household income per capita (below 2000 vs above 2000: OR: $1.34,95 \%$ CI: $1.24-1.45, P<$ 0.001 ) was significantly associated with depression in medical students. Medical students who experienced higher depressive symptoms were those who had a low monthly family income per capita [64, 70, 72], parents with a poor educational background [64], a strained relationship with classmates [35, 72], a broken family [68, 70], financial debts [35], and a family medical history [68].

In the assessment of environmental factors, the social support factor negatively affected depression [68, 70, 75].

\section{Analysis of anxiety}

In the 21 identified studies, 11 reported on the prevalence of anxiety. Based on the 11 articles, the prevalence of anxiety ranged from 8.54 to $88.30 \%$, as shown in Table 2 . The mean prevalence of anxiety was $27.22 \%$. However, 6 different assessment tools were used in different articles. For example, the Beck Anxiety Inventory (BAI) defined a score of $>5$ out of 63 to indicate anxiety. The Hamilton Anxiety Scale (HAMA) defined a score of $>14$ out of 56 to indicate anxiety. The Self-rating Anxiety Scale (SAS) defined a score of $>40$ out of 80 to indicate anxiety.

Amongst all the determinants evaluated, the anxiety analysis identified 20 relevant determinants, including 13 individual factors, six social and economic factors, and one environmental factor. 


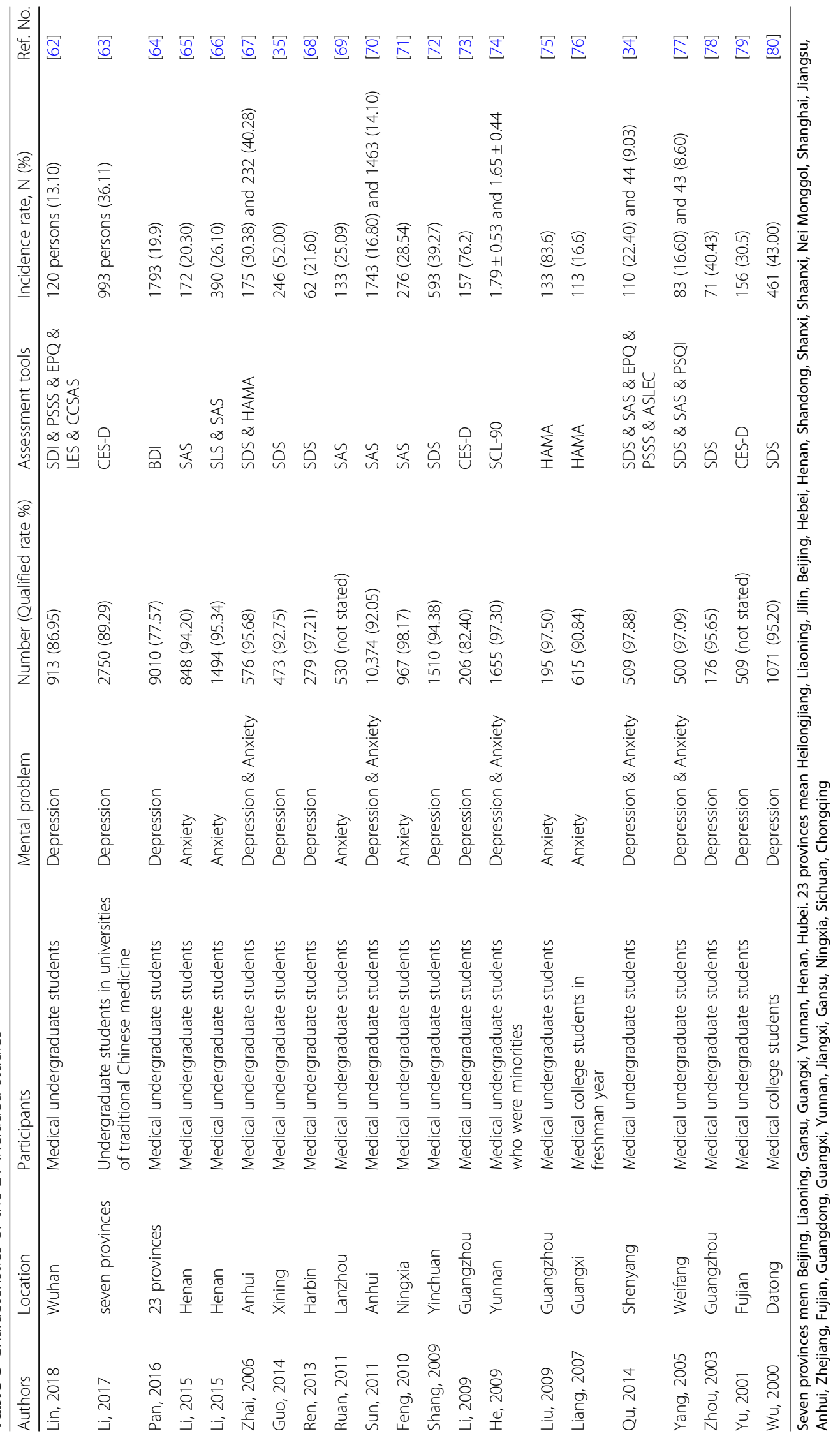


Five individual factor determinants were included in the meta-analysis whereas all the extracted determinants were included in the descriptive analysis. Figure 3 shows the meta-analysis results of the anxiety-related individual factors. After performing the meta-analysis, grade level (low grade vs high grade, OR: $0.66,95 \% \mathrm{CI}$ : $0.61-0.73$, $P<0.00001$ ) and satisfaction with current major (satisfied vs unsatisfied: OR: $0.44,95 \%$ CI: $0.37-0.51, P<$ 0.001 ) were significantly associated with anxiety. Gender, house registry, and being an only child were not significantly associated with anxiety. According to the metaanalysis, the higher grade level students and students who were unsatisfied with their current major were more anxious than their peers.

Medical students who were ethnic minorities [71], lived in rural areas $[65,69,71]$, and had siblings [69, 76] tended to experience anxiety symptoms. Medical students who had poor interpersonal relationships [65], higher academic pressure [65], lower interest and satisfaction with current major [67, 69, 70], poor self-evaluation [69], a poor anticipation of future careers, and sleep deprivation [77] had increased odds of having anxiety.

Regarding current major, the Chinese and Western clinical medicine or nursing students were more depressed than their peers $[75,76]$. Other studies have not reached the same conclusion on this issue [86].

Social and economic factors: anxiety was more likely to affect medical students who had a lower monthly household income per capita (Yuan) [34, 70], parents with a poor educational background [65], on-the-job parents [69], a broken family [70], and had experienced coincidental bad events [67].

Environmental factors: the students who had more social support tended to be less anxious $[67,70]$.

\section{Discussion}

Our study conducted a systematic review of the prevalence and determinants of depression and anxiety amongst medical students in China. Fifteen studies reported on the prevalence of depression amongst medical students whereas 11 studies reported on the prevalence of anxiety.

The prevalence of depression and anxiety were consistent with related studies conducted in other countries. According to a previous study, the overall global prevalence of depression or depressive symptoms amongst medical students was $27.2 \%$ [87]. The prevalence of depression and anxiety outside the North American region was $7.7-65.5 \%$ and $6.0-66.5 \%$, respectively $[87,88]$. In Turkey, depression and anxiety prevalence rates of 39.0 and $35.8 \%$ were reported, respectively [74]. In Egypt, high frequencies of depression (65\%), anxiety (73\%) and stress (59.9\%) were reported. In Nepal, the overall prevalence of depression was $29.9 \%$, and the prevalence of anxiety was $41.1 \%$. The status of anxiety was more severe than the status of depression. A different research scope could explain the discrepancies found in different areas [8].

This study also identified 57 determinants related to depression or anxiety, including 30 individual factors, 25 social and economic factors, and two environmental factors.

In terms of individual factors, first, according to the other studies, the gender differences are changing over time in China; older research tended to report that female students were more depressed or anxious than male students, whereas recent research tended to report the opposite conclusion. This finding is thought to be a result of the higher expectations and responsibilities of male students [62, 77]. However, in other countries, female students normally displayed higher depressive and anxious symptoms [18, 89]. Conversely, studies in some countries reported no gender differences [90]. In China, people still held the perception that men primarily responsible for the "outside part" in family functioning such as earning money whereas women are responsible for the "inside part", such as running the household [91]. Second, the most depressive and anxious grade levels were sophomore and senior students. According to the studies, sophomore students experienced higher academic pressure. Conversely, facing employment pressure, senior students were in a period of transition and feared the future uncertainty. In other studies, freshmen and senior students reported the highest rates of depression and anxiety [89,92]. Third, students with siblings were more depressed and anxious than only children, partly because the latter received more attention from their parents. A previous study reported the same results [93]. Fourth, rural students experienced higher depressive and anxious conditions. Rural students were faced with higher financial stress and family burdens. Medical students from a lower socioeconomic status were more depressed and anxious than their counterparts [64], which suggests that students from low-income families should be given more attention than their peers [94]. Fifth, the degree of dissatisfaction with education was associated with depression and anxiety [95]. In studies from India and Brazil, the low frequency of exercise and high frequency of taking medicines were potential risk factors of depressive and anxious symptoms [86, 96]. In North America, the degrees of depression and anxiety were associated with cigarette addiction, alcoholism, and sleeping deprivation [96]. Medical students in comprehensive colleges were more depressed and anxious than those from medical universities, according to research in Nepal. In Malaysia, the prevalence of depression and anxiety was higher amongst students who had difficulty dealing with 


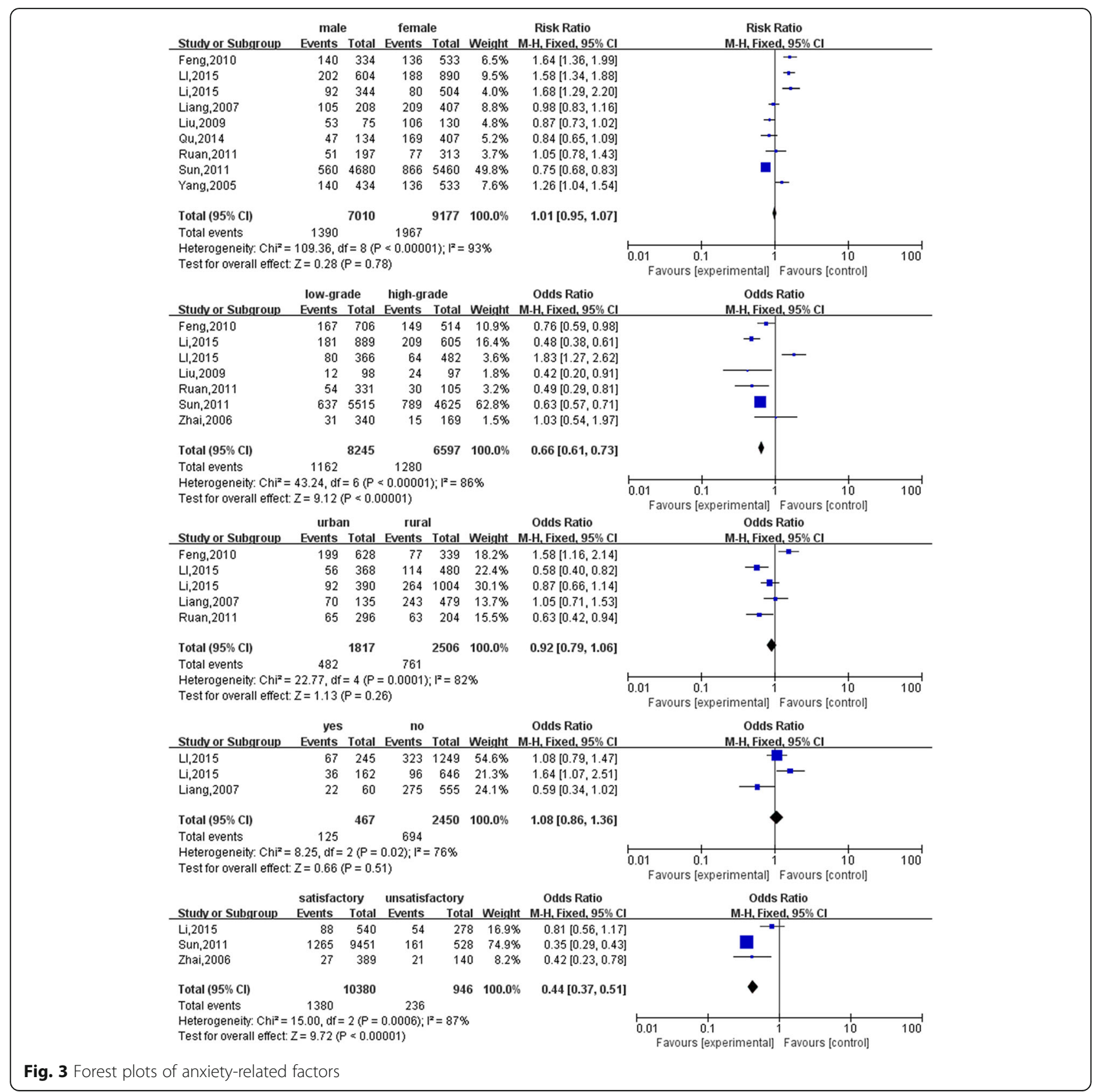

interpersonal relationships and who had a family history of depression and anxiety $[18,20,89,90,92]$.

Social and economic factors included relationships with family members, classmates, teachers, and companions. The fathers' and mothers' educational backgrounds and employment were related to depressive and anxious symptoms. Parents with a higher degree reflected lower depressive and anxious symptoms [97]. Unemployed parents increased the stress of medical students, particularly for students with an unemployed father. The fathers were expected to take up the role of breadwinner whereas the mothers were responsible for the household chores [30]. There was an increasing trend in the prevalence of depressive and anxious symptoms associated with the monthly income per capita of the family. In studies from India, Brazil, Nepal, America, and Malaysia, a higher prevalence of depressive and anxious symptoms was reported amongst students with family problems and a family history of depression and anxiety $[18,90]$.

In the analysis of environmental factors, the results suggested that social support played an important role in moderating depressive and anxious symptoms [98].

One strength of this review was that the analysis of the prevalence of depression and anxiety was based on a 
large sample size of 21 articles and 35,160 individuals. Another strength was the comprehensive analyses of the determinants, particularly the meta-analysis and content analysis. Fifty-nine determinants were extracted from the 21 studies. Thirty-one determinants were significantly associated with depression, and 20 were significantly associated with anxiety. However, some limitations exist in this systematic review. There was significant heterogeneity amongst the individual studies when performing the meta-analysis. To address the problem, more studies should be included by changing search strategy Furthermore, it was difficult to integrate the prevalence of depression and anxiety of included articles, which calculated the values with different assessment tools. The assessment tools had distinct standard, so the integrated results in our article only relatively revealed the true value. In future, the results from different assessment tools should be integrated respectively.

\section{Conclusions}

This systematic review and meta-analysis highlight the problem of depression and anxiety amongst medical students and the related determinants. The findings shed light on taking measures to create potential solutions to diminish mental health diseases. From the perspective of health authorities, the government should invest more money into medical students to satisfy their basic daily needs, especially for the students with financial problem. Early detection and prevention programmes play an important role in alleviating mental problems. From the perspective of medical schools in China, a lot of depressive and anxious medical students were influenced by school-related factors. Schools should strengthen mental support in college, including popularizing psychological knowledge, providing mental health-related courses and lectures, and creating counselling centres. From an individual perspective, students tend to deny being ill because of negative attitudes regarding mental health in society [99]. Therefore, students must confront their mental health problems rather than avoid them. Furthermore, additional studies that explore the environmental factors in the Chinese context are necessary.

\section{Additional file}

Additional file 1: The Search Strategy \& The extracted determinants \& The distribution of determinants \& The Extracted Determinants \& The Significant Results. (DOCX $944 \mathrm{~kb}$ )

\section{Abbreviations}

ADHS: Adult Dispositional Hope Scale; APGAR: Family APGAR Index; ASLEC: Adolescent Self-Rating Life Events Check List; BAl: Beck Anxiety Inventory; BDI: Beck Depression Inventory; BHS: Beck Hopeless Scale; CBM: China Biology Medicine disc; CCSAS: China College Student Adjustment Scale; CES-D: Center for Epidemiologic Studies Depression Scale; CMB: China Medical Board; CNKI: China National Knowledge Internet
Database; CSQ: Coping Style Questionnaire; EF: Environmental factors; EPQ: Eysenck Personality Questionnaire; GRADE: The Grading of Recommendations: Assessment, Development, and Evaluation; HAMA: Hamilton anxiety scale; IF: Individual factors; LES: Life Events Scale; LOT-R: Life Orientation Test-Revised; OR: Odds Ratio; PRISMA: Preferred Reporting Items for Systematic Reviews and Meta-Analyses; PSQI: The Pittsburgh Sleep Quality Index; PSSS: Perceived Social Support Scale; RS14: Resilience Scale-14; SAS: The Self-rating Anxiety Scale; SCL-90: Symptom Checklist 90; SDH: Social determinants of health; SDS: The self-rating Depression Scale; SEF: Social and economic factors; SF-36: The Medical Outcomes Study 36-Item Short-form Health Survey; SLS: Student-life Stress Inventory; SSRS: Social Support Rating Scale; TX: Texas; UK: The United Kingdom; USA: The United State; WHO: World Health Organization

\section{Acknowledgements}

The authors would like to thank the China Medical Board and National Office for Philosophy and Social Sciences of China for their supports.

\section{Authors' contributions}

NZ, YM conceptualized and designed the study. BZ, JLL screened the included articles. NZ put forward outline of the article with $\mathrm{YM}$, made data analyses with BZ, RXH and drafted the manuscript with XW. All authors read and approved the final manuscript.

\section{Funding}

The study was funded by the China Medical Board (CMB), USA. The grant number was 10-029. The funder had no role in the study design, data collection and analysis, interpretation of data, and writing the manuscript. The study was funded by National Office for Philosophy and Social Sciences, China. The grant number was 17ZDA079. The funder had no role in the study design, data collection and analysis, interpretation of data, and writing the manuscript.

\section{Availability of data and materials}

Data sharing is not applicable to this article as no datasets were generated or analyzed during the current study. All databases used in this study are open to the public.

\section{Ethics approval and consent to participate}

Not applicable

\section{Consent for publication}

Not applicable

\section{Competing interests}

The authors declare that they have no competing interests.

\section{Author details}

${ }^{1}$ School of Public Policy and Administration, Xi'an Jiaotong University, Xi'an 710049, China. ${ }^{2}$ Department of Public Policy, City University of Hong Kong, Hong Kong 999077, China.

Received: 14 May 2018 Accepted: 5 August 2019

Published online: 02 September 2019

\section{References}

1. Zhu B, Fu Y, Liu J, Mao Y. Modeling the dynamics and spillovers of the health labor market: evidence from China's provincial panel data. Sustainability. 2018:10:333.

2. Sun T, Gao L, Li F, et al. Workplace violence, psychological stress, sleep quality and subjective health in Chinese doctors: a large cross-sectional study. BMJ Open. 2017;7:e017182.

3. Shan HP, Yang XH, Zhan XL, Feng CC, Li YQ, Guo LL, et al. Overwork is a silent killer of Chinese doctors: a review of Karoshi in China 2013-2015. Public Health. 2017;147:98-100.

4. Elkins C, Plante KP, Germain LJ, Morley CP. Burnout and depression in MS and MS3 years: a comparison of cohorts at one medical school. Fam Med. 2017:49:456-9.

5. Ranasinghe P, Wathurapatha WS, Mathangasinghe Y, Ponnamperuma G. Emotional intelligence, perceived stress and academic performance of Sri Lankan medical undergraduates. BMC Med Educ. 2017;17:41. 
6. Venkatarao E, lqbal S, Gupta S. Stress, anxiety \& depression among medical undergraduate students \& their socio-demographic correlates. Indian J Med Res. 2015;141:354. https://doi.org/10.4103/0971-5916.156571.

7. Kang X, Zhang L, Zhang G, Lv H, Fang F. Research on psychological health status of Chinese 's Young doctors from Hebei province. Neuropsychiatry (2016). 2016;6:85-7.

8. Fawzy M, Hamed SA. Prevalence of psychological stress, depression and anxiety among medical students in Egypt. Psychiatry Res. 2017;255:186-94

9. Rotenstein LS, Ramos MA, Torre M, Segal JB, Peluso MJ, Guille C, et al. Prevalence of depression, depressive symptoms, and suicidal ideation among medical students. JAMA. 2016;316:2214. https://doi.org/10.1001/ jama.2016.17324.

10. Brokalaki H, Matziou V, Thanou J, Zirogiannis P, Dafni U, Papadatou D. Jobrelated stress among nursing personnel in Greek dialysis units. EDTNA ERCA J. 2001:27:181-6.

11. Kamal SM, Al-Dhshan MI, Abu-Salameh KA, Abuadas FH, Hassan MM. The effect of nurses' Perceived Job Related Stressors on Job Satisfaction in Taif Governmental Hospitals in Kingdom of Saudi Arabia. J Am Sci. 2012;8:11925. https://doi.org/10.1017/CBO9781107415324.004

12. Antoniou A-S, Cooper CL, Davidson MJ. Levels of job dissatisfaction and work-related stressors experienced by medical doctors in Greek hospitals. Compassionate Health Care. 2016;3:4. https://doi.org/10.1186/s40639-0160021-z.

13. Abdel Wahed WY, Hassan SK. Prevalence and associated factors of stress, anxiety and depression among medical Fayoum University students. Alexandria J Med. 2017;53:77-84. https://doi.org/10.1016/j.ajme.2016.01.005

14. Bore M, Kelly B, Nair B. Potential predictors of psychological distress and well-being in medical students: a cross-sectional pilot study. Adv Med Educ Pract. 2016:125. https://doi.org/10.2147/AMEP.S96802.

15. Hori D, Tsujiguchi H, Kambayashi Y, Hamagishi T, Kitaoka M, Mitoma J, et al. The associations between lifestyles and mental health using the general health questionnaire 12-items are different dependently on age and sex: a population-based cross-sectional study in Kanazawa, Japan. Environ Health Prev Med. 2016:21:410-21.

16. Wang Y-H, Shi Z-T, Luo Q-Y. Association of depressive symptoms and suicidal ideation among university students in China: A systematic review and meta-analysis. Medicine (Baltimore). 2017;96:e6476. https://doi.org/10.1 097/MD.0000000000006476.

17. Teh CK, Ngo CW, Aniyah R, Vellasamy R, Suresh K. Depression, Anxiety and Stress among Undergraduate Students: A Cross Sectional Study Choon. Open J Epidemiol. 2015;5:260-8.

18. Kunwar D, Risal A, Koirala S. Study of Depression, Anxiety and Stress among the Medical Students in two Medical Colleges of Nepal. Kathmandu Univ Med J. 2016;14:22-6 http://www.ncbi.nlm.nih.gov/pubmed/27892436.

19. Ludwig AB, Burton W, Weingarten J, Milan F, Myers DC, Kligler B. Depression and stress amongst undergraduate medical students. BMC Med Educ. 2015; 15:141.

20. Radeef AS, Ghazi FG. Depression, anxiety and stress with possible sources of stressors among undergraduate medical students in Malaysia. Brunei Int Med J. 2016;12:18-25.

21. Sun X, Niu G, You Z, Zhou Z, Tang Y. Gender, negative life events and coping on different stages of depression severity: a cross-sectional study among Chinese university students. J Affect Disord. 2017;209:177-81. https://doi.org/10.1016/j.jad.2016.11.025.

22. Moutinho IL, Maddalena NC, Roland RK, Lucchetti AL, Tibiriçá SH, Ezequiel OD, et al. Depression, stress and anxiety in medical students: A crosssectional comparison between students from different semesters. Rev Assoc Med Bras. 2017;63:21-8. https://doi.org/10.1590/1806-9282.63.01.21.

23. Shi M, Liu L, Wang ZY, Wang L. The mediating role of resilience in the relationship between big five personality and anxiety among chinese medical students: a cross-sectional study. PLoS One. 2015;10:e0119916.

24. Kumar SG, Kattimani S, Sarkar S, Kar S. Prevalence of depression and its relation to stress level among medical students in Puducherry, India. Ind Psychiatry J. 2017;26:86. https://doi.org/10.4103/ipj.ipj_45_15.

25. Thiemann P, Quince T, Benson J, Wood D, Barclay S. Medical students' death anxiety: Severity and association with psychological health and attitudes toward palliative care. J Pain Symptom Manag. 2015;50:335-342.e2.

26. Piumatti G. Motivation, health-related lifestyles and depression among university students: a longitudinal analysis. Psychiatry Res. 2018;260:412-7.

27. Waqas A, Rehman A, Malik A, Muhammad U, Khan S, Mahmood N. Association of Ego defense mechanisms with academic performance, anxiety and depression in medical students: a mixed methods study. Cureus. 2015. https://doi.org/10.7759/cureus.337.

28. Van Venrooij LT, Barnhoorn PC, Giltay EJ, Van Noorden MS. Burnout, depression and anxiety in preclinical medical students: a cross-sectional survey. Int J Adolesc Med Health. 2015;29:1613.

29. Romo-Nava F, Tafoya SA, Gutiérrez-Soriano J, Osorio Y, Carriedo P, Ocampo $B$, et al. The association between chronotype and perceived academic stress to depression in medical students. Chronobiol Int. 2016;33:1359-68. https:// doi.org/10.1080/07420528.2016.1217230.

30. Raley S, Bianchi SM, Wang W. When do fathers care? Mothers' economic contribution and fathers' involvement in child care. Am J Sociol. 2012;117: 1422-59.

31. Gunjal S, Pateel DGS, Parkar S. Dental anxiety among medical and paramedical undergraduate students of Malaysia. Int J Dent. 2017;2017: 4762576.

32. Erschens R, Herrmann-Werner A, Bugaj TJ, Nikendei C, Zipfel S, Junne F. Methodological aspects of international research on the burden of anxiety and depression in medical students. Ment Health Prev. 2016;4:31-5.

33. Iabal S, Gupta S, Venkatarao E. Stress, anxiety \& depression among medical undergraduate students \& their socio-demographic correlates. Indian J Med Res. 2015;141:354-7. https://doi.org/10.4103/0971-5916.156571.

34. Qu W, Ding N, Pan F-M, Song X-Y, Wu S-S. Depression and anxiety status and related factors of medical college students in a vocational college of Anhui province. Anhui Med Pharm J. 2014;18:71-4.

35. Guo K, Liu M-L, Chen W, Wang Z-F. Investigation of depression and its influencing factors among medical students in Qinghai University. Chinese J Dis Control Prev. 2014;18:475-6.

36. Liu J, Zhang K, Mao Y. Attitude towards working in rural areas: a crosssectional survey of rural-oriented tuition-waived medical students in Shaanxi, China. BMC Med Educ. 2018;18(1):91.

37. Wei $Y$, Huang $Y$, Chen Y. Relationship between depression and type D personality of eight-year medical students. Chin J School Health. 2013;34:1390-2.

38. Moher D, Liberati A, Tetzlaff JAD. PRISMA 2009 flow diagram. PRISMA Statement. 2009;6:1000097.

39. Beck AT, Ward CH, Mendelson M, Mock J, Erbaugh J. An inventory for measuring depression. Arch Gen Psychiatry. 1961;4:561-71.

40. Radloff LS. The CES-D scale: a self-report depression scale for research in the general population. Appl Psychol Meas. 1977;1:385-401.

41. Zung WWK. A self-rating depression scale. Arch Gen Psychiatry. 1965;12:63-70.

42. Wenzel A. Symptom checklist 90. In: The SAGE Encyclopedia of Abnormal and Clinical Psychology; 2017.

43. Beck AT, Epstein N, Brown G, Steer RA. An inventory for measuring clinical anxiety: psychometric properties. J Consult Clin Psychol. 1988;56:893.

44. Zung WWK. A rating instrument for anxiety disorders. Psychosomatics. 1971; 12:371-9.

45. Hamilton M. The Assessment Of Anxiety States By Rating. Br J Med Psychol. 1959:32:50-5.

46. Zimet GD, Dahlem NW, Zimet SG, Farley GK. The Multidimensional Scale of Perceived Social Support. J Pers Assess. 1988;52:30-41.

47. Eysenck HJ, Eysenck SBG. Manual of the Eysenck personality questionnaire; 1975.

48. Holmes $\mathrm{TH}$, Rahe $\mathrm{RH}$. The social readjustment rating scale. J Psychosom Res. 1967;11:213-8.

49. Xiaoyi F, Jianzhong W, Lin XY. Development Of Chinese College Student Adjustment Scale. Stud Psychol Behav. 2005;3:95-101.

50. Scheier MF, Carver CS, Bridges MW. Distinguishing optimism from neuroticism (and trait anxiety, self-mastery, and self-esteem): a reevaluation of the life orientation test. J Pers Soc Psychol. 1994;67:1063-78.

51. Wagnild GM, Young HM. Development and psychometric evaluation of the resilience scale. J Nurs Meas. 1993;1:165-17847.

52. Snyder C, Irving L, Anderson J. Hope and health: measuring the will and the ways. In: Handbook of social and clinical psychology, vol. 162; 1991. p. 285-305.

53. Sarason IG, Levine HM, Basham RB, Sarason BR. Assessing social support: the social support questionnaire. J Pers Soc Psychol. 1983;44:127.

54. Smilkstein $G$. The family APGAR: a proposal for a family function test and its use by physicians. J Fam Pract. 1978;6:1231-9.

55. Gadzella BM. Student-life stress inventory: identification of and reactions to stressors. Psychol Rep. 1994;74:395-402.

56. Roger D, Jarvis G, Najarian B. Detachment and coping: the construction and validation of a new scale for measuring coping strategies. Personal Individ Differ. 1993;15:619-26. 
57. Ware JE, Sherbourne CD. The MOS 36-Item short-form health survey (SF-36): I. Conceptual framework and item selection. Med Care. 1992;30:473-83.

58. Beck AT. Beck hopelessness scale. San Antonio: The Psychological Corporation; 1988

59. Xianchen L, Liu LQ, Yang J, Chai F, Wang AL, Sun DM. Reliability and validity of the adolescents self-rating life events checklist. Chin J Clin Psych. 1997;5: 34-6.

60. Buysse DJ, Reynolds CF, Monk TH, Berman SR, Kupfer DJ. The Pittsburgh sleep quality index: a new instrument for psychiatric practice and research. Psychiatry Res. 1989;28:193-213.

61. Grade working group. Grading of Recommendations Assessment, Development and Evaluation. 2011.

62. Lin F, Zhang L-L, Luo Z-Y, Zhao Q-Q. Depression and Its Influence in Medical Students. Chin J Health Psychol. 2018;26:622-7.

63. Li X, Yu L-L, Gao J-N, Pei Y, Xu F-Q, Kong J-H. Epidemiological survey of the depressive symptoms among traditional Chinese medicine college students. Chin Med Her. 2017;14:49-52

64. Pan X-F, Wen Y, Zhao Y, Hu J-M, Li S-Q, Zhang S-K, et al. Prevalence of depressive symptoms and its correlates among medical students in China: a national survey in 33 universities. Psychol Health Med. 2016;21:882-9. https://doi.org/10.1080/13548506.2015.1127395.

65. Li Q. Investigation and analysis of anxiety of undergraduates in a medical College of Henan Province. Chongqing Med. 2015;44:2237-41.

66. Li N, Zhao C, Li Z, Xu L, Zhu P-S. Relationship between life stress and anxiety among students in a medical university. Occup Health. 2015;31: 3467-9.

67. Zhai D-C, Pan X-D, Han S-L, Mou J, Zhou X-S. Epidemiological characteristics and related factors of depression and anxiety in medical students. Chin J School Health. 2006;27:217-9.

68. Ren X-H, Liu Z-X, Sun H-W. Depression epidemiological studies of college students. J Harbin Med Univ. 2013;47:471-4.

69. Ruan Y, Wen S-L, Yong-Qin C. Anxiety status and risk factors of medical college students in Lanzhou. Chinese Prim Health Care. 2011;17:73-5.

70. Sun L, Sun L-N, Sun Y-H, Yang L-S, Wu H-Y, Zhang D-D, et al. Correlations between psychological symptoms and social relationships among medical undergraduates in Anhui Province of China. Int J Psychiatry Med. 2011;42: 29-47. https://doi.org/10.2190/PM.42.1.c.

71. Feng T-Y. Investigation and analysis of psychological anxiety and influencing factors of medical students. J Ningxia Med Univ. 2010;32:786-8.

72. Shang Y-X, Yan S-Z, Zhu F-P. A cross-sectional study of suicide ideation and depression among medical students and its influencing factors. Mod Prev Med. 2009;36:3092-4.

73. Li W-W, Li X-C, Luo Y-W, Liao M-S, Lv W-L, Wei X. A survey of psychological distress of medical undergraduates in Guangzhou area. Chinese J Gen Pract. 2009;7:1220-1.

74. He L-M, Wang Y-Y, Chen Y, Mu C-X, Wang X-W. Cross sectional study on mental health of 1655 minority medical students. Soft Sci Health. 2009;23: 294-7.

75. Liu K-R, Hu G-F, Zhang M-Y, Yan Y-X, Nie J. Psychological anxiety evaluation and analysis of graduates at a medical university under employment pressure. J South Med Univ. 2009;29:1071-2.

76. Liang X-R, Long S-K, Wang X-L. A survey of the anxiety status of medical students in the first grade of college in Guangxi. Mod Prev Med. 2007;34: 2701-3

77. Yang X-Z, Chen J-W, Feng G-S. Correlation between sleep quality and anxiety and depression in medical students. Acta Acad Med Weifang. 2005; 27:100-2.

78. Zhou R, Yang C-H, Pan J. Investigation and analysis of depression and related factors among students of key medical college in Guangzhou area. Nerv Dis Ment Health. 2003;3:367-8.

79. Yu M, Cao J-P. Investigation of mental health problems of 509 medical students. Strait J Prev Med. 2001;7:32-3.

80. Wu H-L, Ma C-G, Wang L-S, Wang F-F, Wang Y-R. Analysis of depression and its influencing factors in medical school students. Chin J Health Psychol. 2000;8:279-82

81. WHO, World Health Organization. Mental Health Action Plan (2013-2020). Geneva; 2013

82. WHO|social determinants of health. https://www.who.int/social determinants/en/. Accessed 19 Mar 2019.

83. World Health Organization. Social Determinants of Mental Health; 2014. https://doi.org/10.3109/09540261.2014.928270.
84. Compton MT, Shim RS. The social determinants of mental health. Focus (Madison). 2015;13:419-25. https://doi.org/10.1176/appi.focus.20150017.

85. Higgins JPT, Thompson SG, Deeks JJ, Altman DG. Measuring inconsistency in meta-analyses. BMJ Br Med J. 2003;327:557-60.

86. Yadav R, Gupta S, Malhotra A. A cross sectional study on depression, anxiety and their associated factors among medical students in Jhansi, Uttar Pradesh, India. Int J Community Med Public Health. 2016;3:1209-14.

87. Puthran R, MWB Z, Tam WW, Ho RC. Prevalence of depression amongst medical students: a meta-analysis. Med Educ. 2016;50:456-68. https://doi. org/10.1111/medu.12962.

88. Hope V, Henderson M. Medical student depression, anxiety and distress outside North America: a systematic review. Med Educ. 2014;48:963-79. https://doi.org/10.1111/medu.12512.

89. Brenneisen Mayer F, Souza Santos I, Silveira PSP, Itaqui Lopes MH, de Souza ARND, Campos EP, et al. Factors associated to depression and anxiety in medical students: a multicenter study. BMC Med Educ. 2016;16:282. https:// doi.org/10.1186/s12909-016-0791-1.

90. Mihăilescu Al, Diaconescu LV, Ciobanu AM, Donisan T, Mihailescu C. The impact of anxiety and depression on academic performance in undergraduate medical students. Eur Psychiatry. 2016;33:S284. https://doi. org/10.1016/j.eurpsy.2016.01.761.

91. Wang J, Miller JK, Zhao X. Family Functioning and Social Support in Men and Women Diagnosed with Depression in China. Contemp Fam Ther. 2014:36:232-41.

92. Ediz B, Ozcakir A, Bilgel N. Depression and anxiety among medical students: examining scores of the beck depression and anxiety inventory and the depression anxiety and stress scale with student characteristics. Cogent Psychol. 2017;4. https://doi.org/10.1080/23311908.2017.1283829.

93. Yang B, Ollendick TH, Dong Q, Xia Y, Lin L. Only children and children with siblings in the People's republic of China: levels of fear, anxiety, and depression. Child Dev. 1995;66:1301-11.

94. Zimmerman FJ, Katon W. Socioeconomic status, depression disparities, and financial strain: what lies behind the income-depression relationship? Health Econ. 2005;14:1197-215.

95. Christensson A, Vaez M, Dickman PW, Runeson B. Self-reported depression in first-year nursing students in relation to socio-demographic and educational factors: a nationwide cross-sectional study in Sweden. Soc Psychiatry Psychiatr Epidemiol. 2011;46:299-310.

96. Dyrbye LN, Thomas MR, Shanafelt TD. Systematic review of depression, anxiety, and other indicators of psychological distress among U.S. and Canadian medical students. Acad Med. 2006;81:354-73.

97. Zhai H, Chen L, Yang Y, Sun H, Pan H, He J, et al. Family and college environmental exposures mediate the relationship between parental education and depression among college students. PLoS One. 2016;11: e0151759.

98. Grav S, Hellzèn O, Romild U, Stordal E. Association between social support and depression in the general population: the HUNT study, a cross-sectional survey. J Clin Nurs. 2012;21:111-20.

99. Mahto R, Verma P, Verma A, Singh A, Chaudhury S, Shantna K. Students' perception about mental illness. Ind Psychiatry J. 2010;18:92.

\section{Publisher's Note}

Springer Nature remains neutral with regard to jurisdictional claims in published maps and institutional affiliations.

Ready to submit your research? Choose BMC and benefit from:

- fast, convenient online submission

- thorough peer review by experienced researchers in your field

- rapid publication on acceptance

- support for research data, including large and complex data types

- gold Open Access which fosters wider collaboration and increased citations

- maximum visibility for your research: over $100 \mathrm{M}$ website views per year

At BMC, research is always in progress.

Learn more biomedcentral.com/submissions 